\title{
Application of Aluminium Oxide Nanoparticles to Enhance Rheological and Filtration Properties of Water Based Muds at HPHT Conditions
}

Sean Robert Smith ${ }^{1}$, Roozbeh Rafati*1, Amin Sharifi Haddad ${ }^{1}$, Ashleigh Cooper $^{2}$, Hossein Hamidi ${ }^{1}$

${ }^{1}$ School of Engineering, University of Aberdeen, Aberdeen, United Kingdom, AB24 3UE

${ }^{2}$ Baroid Drilling Fluid Laboratory, Halliburton, Dyce, Aberdeen, United Kingdom, AB21 OGN

\begin{abstract}
Drilling fluid is of one of the most important elements of any drilling operation, and through ever advancing technologies for deep water and extended reach drillings, enhancement of drilling fluids properties for such harsh conditions need to be investigated. Currently oil based fluids are used in these types of advanced drilling operations, as their performance at high pressure and high temperature conditions, and deviated wells are superior compared to water based fluids. However, the high costs associated with using them, and environmental concerns of such oil base fluids are drawbacks of them at the moment. In this study, we tried to find a solution for such issues through investigation on the potential application of a new nano-enhanced water base fluid for advanced drilling operations. We analysed the performance of water base drilling fluids that were formulated with two type of nanomaterials (aluminium oxide and silica) at both high and low pressure and temperature conditions (high: up to $120^{\circ} \mathrm{C}$ and $500 \mathrm{psi}$, low: $23{ }^{\circ} \mathrm{C}$ and $14.7 \mathrm{psi}$ ). The results were compared with a base case drilling fluid with no nanomaterial, and they showed that there is an optimum concentration for aluminium oxide nanoparticles that can be used to improve the rheological and filtration properties of drilling fluids. These results demonstrated that nano-enhanced drilling fluids have an improved thermal stability at heightened temperatures and can withstand the harsh conditions in advanced drilling operations while they impose a lower environmental impact and capital costs.
\end{abstract}

\section{Keywords}

Drilling Fluids, Aluminium Oxide Nanoparticles, HPHT Conditions, Rheological Properties, Mud Filtrate

\section{Introduction}

Offshore exploration drilling and appraisal wells are among the highest capital costs at as high as $60 \%$ in the development of an oil field [1]. The costs and depth of drilling based 
on API data show that with increasing depth, the cost of drilling increases exponentially [2]. Thus a drilling fluid that provides good stability in bottom hole conditions and reduces non-productive time is one of the requirements to keep the costs down [3]. In recent years, the focus of oil and gas companies has shifted towards deeper and arctic reservoirs which can typically reach extreme temperatures [4-6], therefore, the industry needs to come up with viable solutions to keep drilling costs down.

Although the use of oil based fluids (OBF) showed superior performance to water based fluids (WBF), it can lead to high costs, especially in ultra-deep drilling operations, in addition to the waste management challenges compared to water based fluids $[4-6,7,8]$. OBFs superior performance includes improved rheology and reduced friction factor that creates less wear on the drill string and a lower chance of stuck pipe [4,5]. In order to have a WBF which provides similar levels of properties (with lower toxicity), we would require additives such as nanomaterials $[8,9]$.

Nanotechnology is a relatively new technology which has been gaining advancements in different areas such as civil and material engineering [10], and within the oil and gas industry over the past decade $[11,12,13]$. The concept of nanotechnology within oil and gas has shown a significant momentum in exploring deep-water drilling and ultra-deep formations $[4,5]$.

Nanoparticles (NPs) are defined as particles with the size between 1-100 nm and characteristically have a large surface area to volume ratio compared to micro sized particles, hence behave in a different physical nature, such as their heat transfer properties, than larger particles [10]. The potential benefit of adding nanomaterials to drilling fluids is to increase wellbore stability and drilling efficiency [14-16], which reduces drilling costs. This is achieved through reduced filtration of drilling fluids (reduced filter cake thickness) which can prevent differential sticking [17], improved rheological properties that affects the transport of cuttings to the surface $[5-6,13]$, reduced friction and hence lower torque and drag on the drill pipes, and reduced wear during horizontal and directional drilling operations [17]. Furthermore, nanoparticles can improve heat transfer properties of drilling fluids which will reduce thermal degradation of downhole equipment [18-23]. Lower drilling costs through the use of nanoparticles [24] instead of expensive additives would then allow drilling operations to become economically viable. 
There are several studies on the application of silica nanoparticles to improve rheological properties of drilling fluids [12, 14-16, 25]; mud filtrate reduction [9], friction reduction [16] and shale inhibitions [8, 12], where most of them have been performed at low pressure/low temperature conditions [14-18]. However, the effect of metal oxide nanoparticles such as copper, iron, zinc and aluminium oxides on mud properties are still relatively unknown and needs further investigations specially at high pressure and temperature conditions.

Mahmoud et al. in 2016 showed that as the concentration of silica NPs increased, an increase in porosity and permeability of the filter cake occurred due to an increase in agglomeration, whereas an iron based NPs showed a significant reduction in filtrate volume (43\%) for NPs concentration of $0.5 \mathrm{wt} \%$ [26]. It was reported that at heightened conditions, iron NPs stabilise the viscosity and yield stress of water based fluids up to 93 ${ }^{\circ} \mathrm{C}$, and minor changes to the fluids rheological properties were observed at $177^{\circ} \mathrm{C}$, after aging the samples for 16 hours. They also showed that filtration properties can be improved with the addition of iron NPs at HPHT (High Pressure High Temperature) conditions, and the optimum NPs concentration was $0.5 \mathrm{wt} \%$ with the lowest filtrate volume.

Aluminium oxide NPs have shown exceptional cooling properties in nanofluids [27], however, very little research has been conducted in determining their applications to drilling fluids. The study conducted by Anyanwu and Unubi in 2016, mainly focused on different particle size distrbutions of aluminium oxide NPs, and the results were monitored for NPNT (Normal Pressure Normal Temperature) filtration test with NPs concentration of $2 \mathrm{wt} \%$ [28]. Based on their analysis they found that the addition of aluminium oxide greatly reduces fluid loss leading less formation damage, and the filtration volume is dependent on the particle size distribution of the drilling fluid. Furthermore, in another study, Amarfio and Abdulkadir investigated the thermal stability of water based fluids with added aluminium oxide NPs, with no focus on the filtration properties [29]. They found that at higher temperatures, addition of aluminium oxide NPs could maintain the shear stress of the fluid. These studies showed that aluminium oxide NPs have potentials to improve physiochemical properties of drilling fluids, however, their rheological behaviour and filtration properties at high temperature conditions have not been explored. 
The aluminium oxide due to its high thermal conductivity can dissipate heat efficiently from fluid through Brownian motion. Therefore, fluid is less affected by the temperature increase, and it keeps its fluid form rather than degrading into a solid, and as a result the shear stress profile stays low when increasing the temperature from 20 up to $80{ }^{\circ} \mathrm{C}$. This also helps fluid through dynamic ageing to keep its form with a lower changes in shear stress profile compared to the base sample and the sample with silica NPs, which might be explained through the theory of Brownian motion [19]

Several studies have been also performed in the past to confirm that nanofluids have higher thermal conductivities as compared to the base fluids. Liu et al. [20] obtained $12.4 \%$ thermal conductivity enhancement when ethylene glycol was dispersed with 1 vol\% Carbone Nanotube (CNT). Ding et al. [21] obtained as much as $80 \%$ enhancement with only $1 \mathrm{wt} \%$ of CNT dispersed in water. Farbod et al. [22] yielded approximately $15 \%$ enhancement when $0.5 \mathrm{vol} \% \mathrm{CNT}$ was added into water. The wide variation in thermal conductivity enhancement of CNT nanofluids can be attributed to several factors such as Brownian motion, nanolayer formation, nanoparticle clustering, size and volume fraction of nanoparticles [23-24].

Silica nanoparticles as an industry standard nanoparticle have been reported in the previous literatures as a viscosity modifier, filtration loss controller, friction reducer and shale inhibitor $[12,14-16,25]$. The silica nanoparticles are also chemically inert and do not react with the reservoir rock and fluid to alter their chemical properties which make them more popular for oil and gas industry. In this paper, we used silica nanoparticles as a benchmark and compared the results with aluminium oxide nanoparticles.

In this study we evaluated the apparent viscosity (AV), plastic viscosity (PV), yield point (YP), gel strength after 10 seconds and 10 minutes (Gel 10s, Gel 10min), and filtration properties of water based fluids (WBFs) with added aluminium oxide NPs at both low and high temperature conditions as standard practice of drilling fluids characterisations. The results provide us with an understanding of the feasibility of using the modified water based fluids in high temperature and ultra-deep formations.

The rheology of drilling fluids ideally exhibit shear thinning behaviour, to create less resistance at high shear rates. At low shear rates, (for instance when mud circulation has stopped) the viscosity should be high enough to prevent transported cuttings falling back 
down the wellbore under the influence of Stokes' Law. The ideal model the drilling fluid follows is the Herschel-Buckley model [30], as shown by Equation 1.

$\tau=\tau_{0}+K \gamma^{n}$

Where $\tau$ is the shear stress $\left(\mathrm{lb} / 100 \mathrm{ft}^{2}\right), \tau_{0}$ is the yield point $\left(\mathrm{lb} / 100 \mathrm{ft}^{2}\right), K$ is the consistency index, $\gamma$ is the shear rate $\left(\mathrm{s}^{-1}\right)$ and $n$ is the flow behaviour index (dimensionless) which should be less than 1 for shear thinning fluids.

Apparent viscosity (AV); is defined as the ratio of stress to rate of strain of a liquid, plastic viscosity (PV); is the resistance to the flow of a fluid, yield point (YP); is the shear stress at zero shear strain, and gel strength at 10-seconds (Gel10s) and 10-minutes (Gel10min) are shear stress measured at low shear rate after the fluid remains quiescent for a certain period of time (10 seconds and 10 minutes based on the standard API; American Petroleum Institute, procedure), through these measurements we can evaluate fluids ability to act like a gel and suspend cuttings and weighting materials when circulation is ceased.

\section{Methodology}

Apparent viscosity (AV), plastic viscosity (PV) and yield point (YP), gel strength (Gel10s,Gel10min) and filtration properties of a water base fluid at both NPNT $\left(23{ }^{\circ} \mathrm{C}\right.$ and $14.7 \mathrm{psi}$ ) and HPHT (up to $120^{\circ} \mathrm{C}$ and $500 \mathrm{psi}$ ) conditions were measured, thereafter we proposed the improvement that we can achieve through nanofluids. Therefore, a water based drilling fluid with added aluminium oxide NPs will be compared against a base sample with no NPs, and comparisons of fluids with aluminium oxide NPs and the samples with silica NPs with the same concentrations will be presented. In addition, shear stress versus shear rate was evaluated. Filtration test was performed based on the standard API filter press test.

Furthermore, the nano-enhanced WBF properties were determined at heightened temperatures to assess the feasibility of using them in ultra-deep formations. Analysis of the rheology of the samples were performed at $50{ }^{\circ} \mathrm{C}$ and $80{ }^{\circ} \mathrm{C}$ to determine the stability of nanofluids across a range of temperatures. HPHT filtration test was conducted at 120 ${ }^{\circ} \mathrm{C}$ and 500 psi for 30-minutes. For three samples of base WBF, and samples containing $0.2 \mathrm{wt} \%$ of silica and aluminium oxide NPs, rheology and HPHT filtration test were also measured after being dynamically aged for 16 hours at $120{ }^{\circ} \mathrm{C}$ and $100 \mathrm{psi}$. This can be used to emulate downhole conditions by constantly rolling for a large period of time to 
determine how the prolonged exposure to heat can alter the fluid properties which has been recommended by previous studies [15, 26, and 31].

\section{Materials}

Drilling fluid samples were prepared based on the typical formulation currently used in drilling operations. Table 1 shows the WBF formulation with concentrations of silica and aluminium oxide NPs (supplied from Sigma-Aldrich) with concentrations ranging from $0.1 \mathrm{wt} \%$ up to $1 \mathrm{wt} \%$. The rest of mud components were provided by M-I Swaco Company.

Table 1. List of materials and properties used to make the water based drilling fluids.

\begin{tabular}{|c|c|c|c|c|c|}
\hline Material & Mass/Conc. & $\begin{array}{l}\text { Chemical } \\
\text { Formula }\end{array}$ & Particle size & pH & Purpose \\
\hline Water & $350 \mathrm{ml}$ & $\mathrm{H}_{2} \mathrm{O}$ & N/A & $\begin{array}{l}6.5- \\
7.5\end{array}$ & $\begin{array}{l}\text { Continuous } \\
\text { phase }\end{array}$ \\
\hline Bentonite & $22.5 \mathrm{~g}$ & $\begin{array}{l}\mathrm{Al}_{2} \mathrm{O}_{3} \cdot 4 \mathrm{SiO}_{2} \cdot \mathrm{H} \\
{ }_{2} \mathrm{O}\end{array}$ & $1-100 \mu \mathrm{m}$ & $8-10$ & Viscosifier \\
\hline Barite & $20.3 \mathrm{~g}$ & $\mathrm{BaSO}_{4}$ & 3-74 $\mu \mathrm{m}$ & 7-8 & \multirow{2}{*}{$\begin{array}{l}\text { Weighting } \\
\text { agent } \\
\text { Filtration } \\
\text { control }\end{array}$} \\
\hline $\begin{array}{l}\text { Polyanionic } \\
\text { cellulose }\end{array}$ & $0.5 \mathrm{~g}$ & $\mathrm{C}_{23} \mathrm{H}_{28} \mathrm{~N}_{4} \mathrm{O}_{2}$ & $1-100 \mu \mathrm{m}$ & 7-8 & \\
\hline Silica NPs & $0.1,0.2,0.5,1 \mathrm{wt} \%$ & $\mathrm{SiO}_{2}$ & $12 \mathrm{~nm}$ & 4.2 & \multirow{2}{*}{$\begin{array}{l}\text { Viscosifer/ } \\
\text { filtration } \\
\text { control }\end{array}$} \\
\hline $\begin{array}{l}\text { Aluminium } \\
\text { oxide NPs }\end{array}$ & $0.1,0.2,0.5,1 \mathrm{wt} \%$ & $\mathrm{Al}_{2} \mathrm{O}_{3}$ & $<50 \mathrm{~nm}$ & 4.5 & \\
\hline
\end{tabular}

The base sample of the drilling fluid was prepared by adding $350 \mathrm{ml}$ of distilled water with $22.5 \mathrm{~g}$ of Wyoming bentonite which is a typical ratio for water based drilling fluids. To increase the density of fluid up to 9 pounds per gallon (ppg), $20.3 \mathrm{~g}$ of barite was used, and $0.5 \mathrm{~g}$ of Polyanionic Cellulose (PAC) and Xanthan Gum (XG) were added as filtration control additive and rheology stabiliser respectively.

Aluminium oxide NPs have relatively high thermal conductivity, around $30 \mathrm{Wm}^{-1} \mathrm{~K}^{-1}$, and surface area of $40 \mathrm{~m}^{2} / \mathrm{g}$ compared to silica NPs which have thermal conductivity of $1.4 \mathrm{Wm}^{-1} \mathrm{~K}^{-1}$ and surface area of $175-225 \mathrm{~m}^{2} / \mathrm{g}$. Figure 1 shows the Scanning Electron Microscope (SEM) images of silica and aluminium oxide NPs. It can be seen that silica NPs have a much more powdery texture with few agglomerates whereas majority of the aluminium oxide NPs have agglomerated into small balls. 


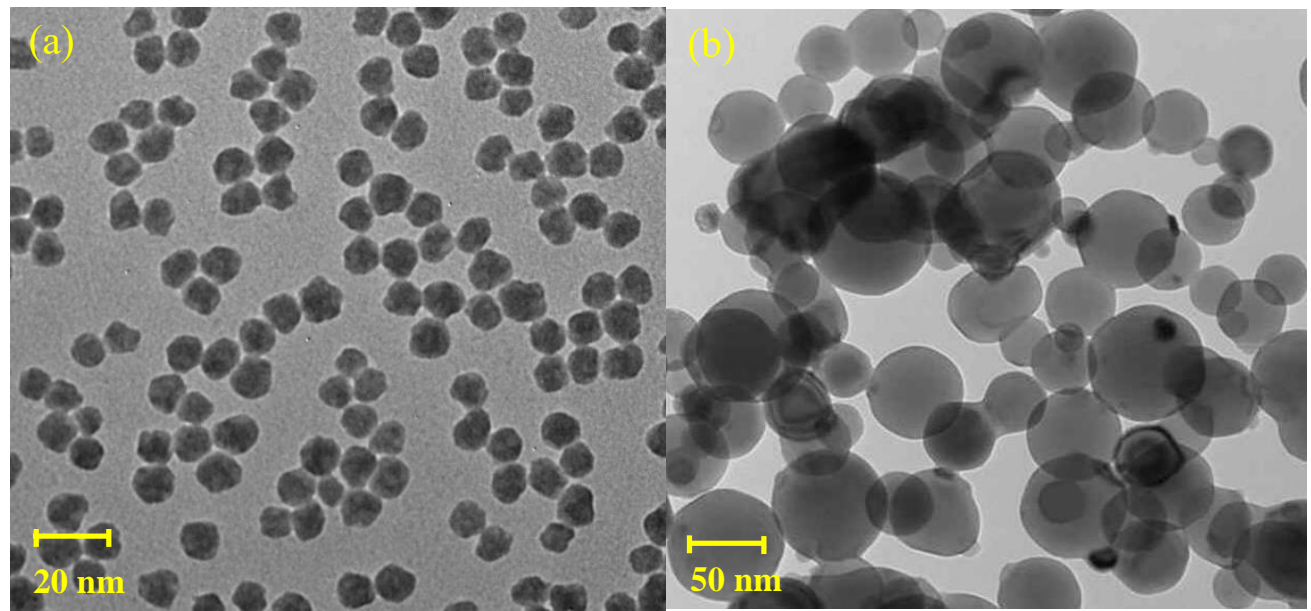

Figure 1: (a) SEM image of silica NPs, (b) SEM image of aluminium oxide NPs

\section{Experimental equipment}

The rheology of the samples were tested through using an OFITE- 800 viscometer at NPNT conditions, and a Fann 35SA viscometer to measure them at heightened temperatures. The filtration properties at NPNT were measured by an OFITE filter press equipment, and at HPHT conditions a Fann HPHT $175 \mathrm{ml}$ filter press was used. Filter paper used for filtration tests have a particle size retention range of 2-5 $\mu \mathrm{m}$. Please see supplementary material for more details about the equipment.

\section{Experimental procedure}

In sample preparation procedure, 15 minutes was set for stirring and mixing after adding each component (water, bentonite, barite). To improve the rheological properties of water based fluids typically xanthan gum and Polyanionic Cellulose will be added, we used $0.5 \mathrm{~g}$ of each in our base sample. Then modified samples with addition of NPs were prepared and their rheological (AV, PV, YP, Gel10s, and Gel10min), and filtration properties were tested. Thereafter, the hot rolling of three samples, a base sample and two samples containing different NPs, was performed. All the samples were left to age for 16 hours before testing has begun. Figure 2 shows the steps were taken to analyse the properties of drilling fluids in this study. 


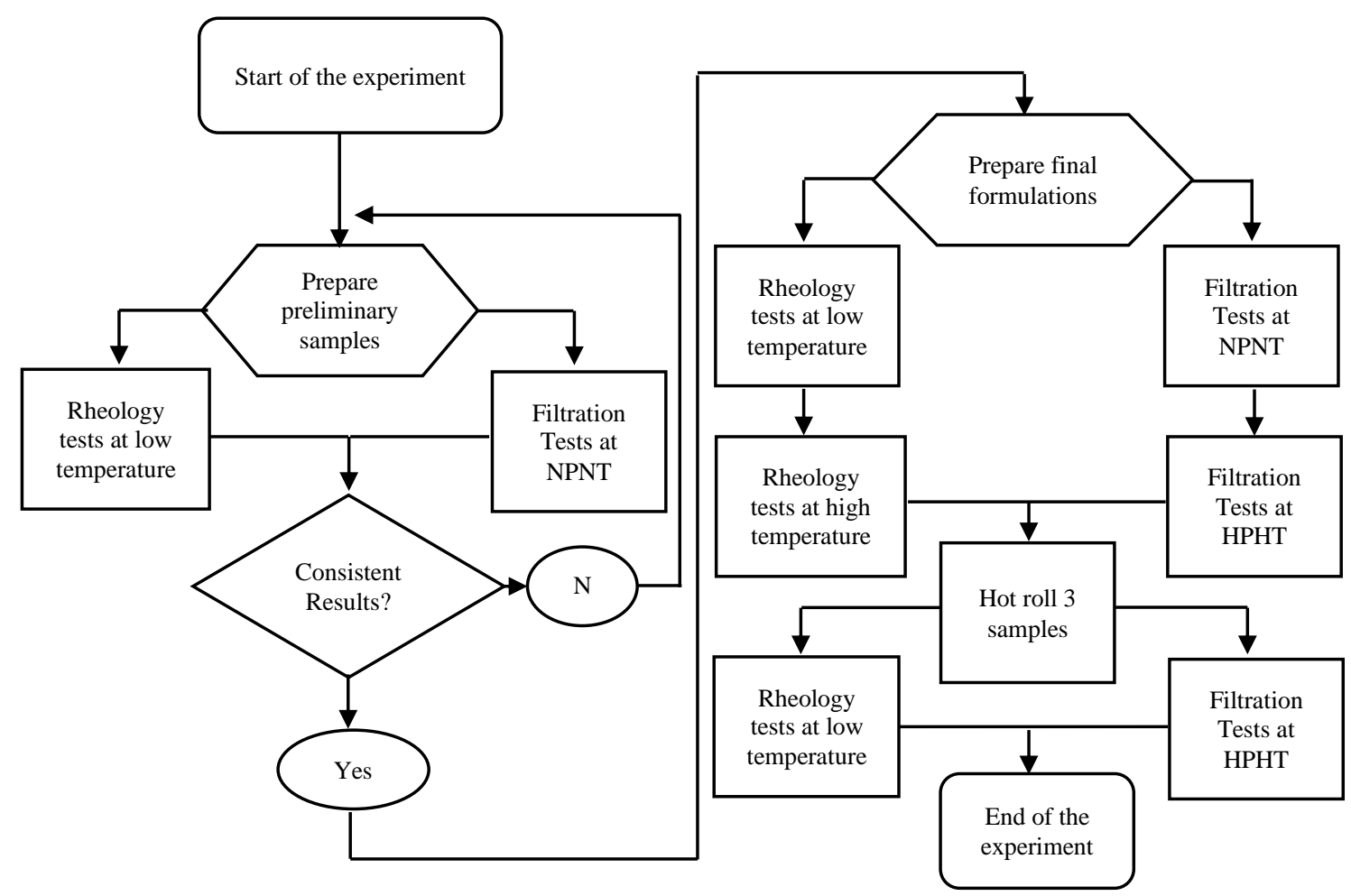

Figure 2: Flowchart of the experimental procedure

To determine the apparent viscosity (AV), plastic viscosity (PV) and yield point (YP), the following equations are used. Viscosities are reported in centipoise, and, the yield point and gel strength are in $\mathrm{lbf} / 100 \mathrm{ft}^{2}$ unless otherwise stated.

$$
\begin{aligned}
& A V=R P M_{600} / 2 \\
& P V=R P M_{600}-R P M_{300} \\
& Y P=R P M_{300}-P V
\end{aligned}
$$

$\mathrm{AV}$ is calculated from the shear stress when the shear rate, measured at 600 revolutions per minute (RPM600), and PV is calculated from the shear stresses at 600 revolutions per minute $\left(\mathrm{RPM}_{600}\right)$ and 300 revolutions per minute $\left(\mathrm{RPM}_{300}\right)$. Finally, YP is calculated from the shear stress at 300 revolutions per minute $\left(\mathrm{RPM}_{300}\right)$ and the calculated value for PV. For the HPHT filtration tests, the filter press area is one half of the normal filter press equipment used for NPNT conditions, therefore, the HPHT filtrate volume needs to be doubled for comparison purposes as recommended by API standards.

Each experiment was repeated three times and their average value is reported. Standard deviation of one set of each experiment is calculated and added as error bars for NPNT tests.

The coding for the samples are shown in Table 2. There are a total of 9 formulations, one base sample, and four samples with different concentrations of nanoparticles ranging from 0.1 to $1 \mathrm{wt} \%$. 
Table 2: The codings for samples with two different NPs and their concentrations in weight percent

\begin{tabular}{llllll}
\hline wt \% of NPs & $\mathbf{0 . 0 0}$ & $\mathbf{0 . 1 0}$ & $\mathbf{0 . 2 0}$ & $\mathbf{0 . 5 0}$ & $\mathbf{1 . 0 0}$ \\
\hline Silica & BP & S2P & S3P & S4P & S5P \\
Aluminium oxide & BP & A2P & A3P & A4P & A5P \\
\hline
\end{tabular}

\section{Results and discussion}

The results of the experiments were divided into two main parts. First part presents apparent viscosity (AV), plastic viscosity (PV), yield point (YP), and gel strength (Gel10s, Gel10min), and filtration properties of a WBF in the presence of NPs that were conducted at NPNT conditions. In the next part, analysis of the WBF enhanced by NPs at HPHT conditions were discussed. In this part the same rheological properties at elevated temperatures, HPHT filtration, and properties before and after hot rolling were investigated. Density remained at $9 \pm 0.1 \mathrm{ppg}$ and $\mathrm{pH}$ at $8.5 \pm 0.5$ throughout the experiments.

\section{Rheological and filtration properties of a WBF (Nanofluid) at NPNT conditions}

In this section, the rheological and filtration properties of the nanofluid at NPNT conditions were presented.

Figure 3 shows shear stress against shear rate of the base drilling fluid without nanoparticles at $23{ }^{\circ} \mathrm{C}$ and $14.7 \mathrm{psi}$. As it can be seen from the figure, shear stress was increased with the shear rate with a shear thinning behaviour.

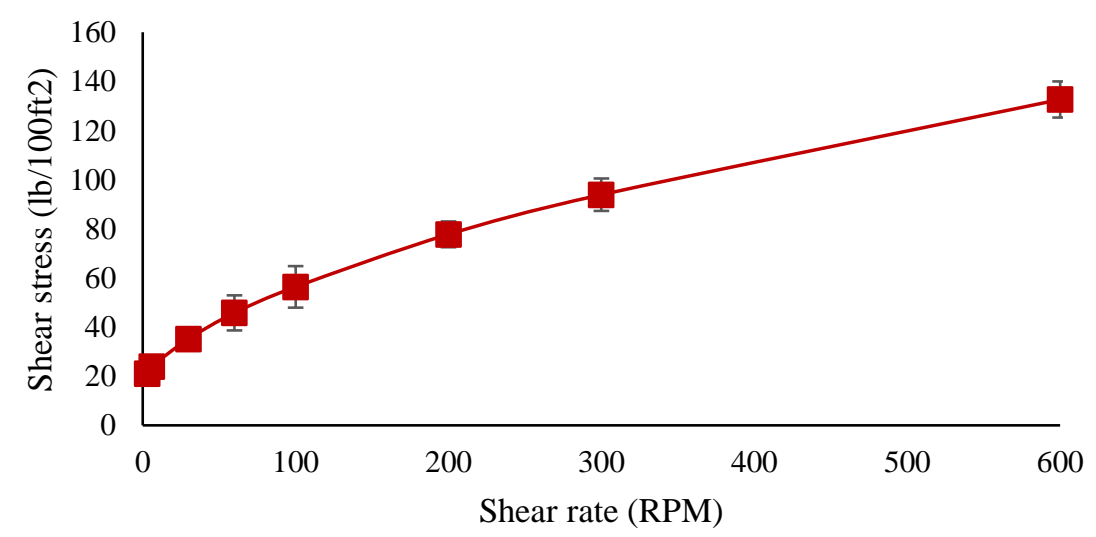

Figure 3: Shear stress against shear rate of the base fluid without nanoparticles at $23^{\circ} \mathrm{C}$ and 14.7 psi (NPNT conditions)

Figure 4 shows shear stress against shear rate for different WBFs tested in this study. It can be seen that the addition of NPs in any concentration reduces the magnitude of shear 
stress. Aluminium oxide NPs with concentrations more than $0.2 \mathrm{wt} \%$ show a significant reduction in shear stress, whereas the samples with silica NPs have a steady reduction of shear stress with increasing NPs concentration.

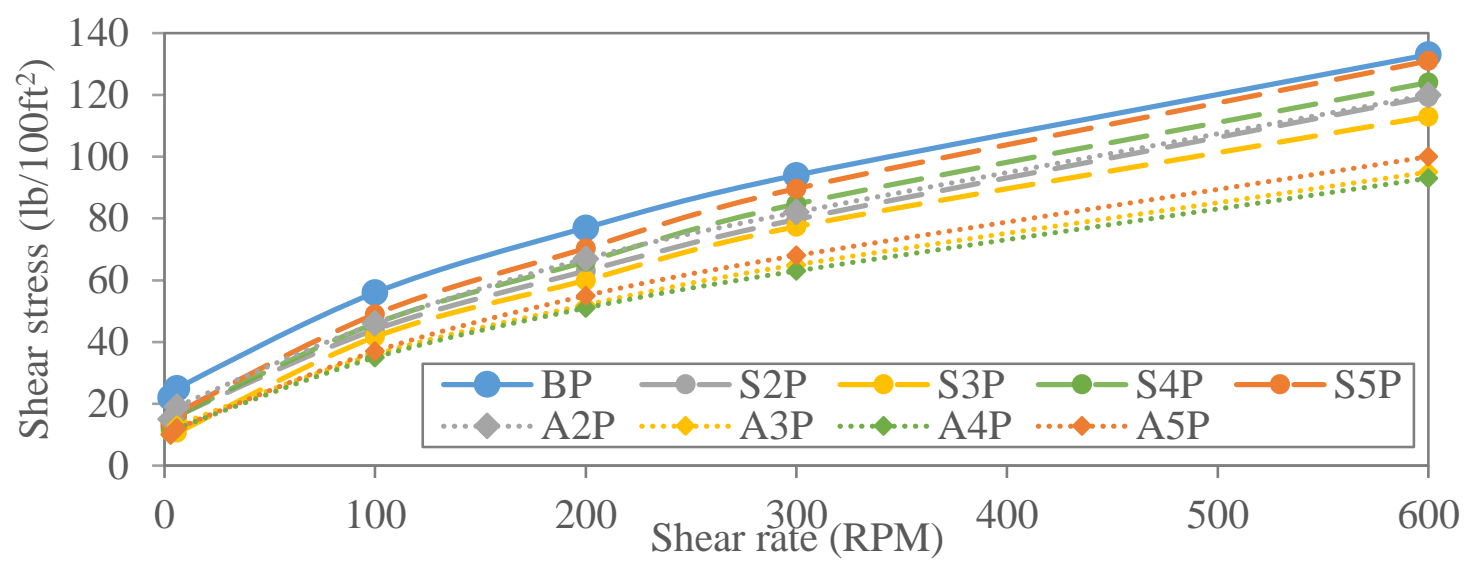

Figure 4: Shear stress against shear rate at NPNT conditions

Furthermore, analysis of the apparent viscosity (AV), plastic viscosity (PV), yield point (YP), and gel strength (Gel10s, Gel10min) as shown in Figure 5, demonstrates the addition of silica NPs produces the lowest AV, PV and gel strengths for the sample with the concentration of $0.2 \mathrm{wt} \%$. The samples with aluminium oxide NPs show a decreasing trend for the same properties with increasing NPs concentration up to concentrations between 0.2 and $0.5 \mathrm{wt} \%$, and again starts to rise slightly at the higher concentrations.
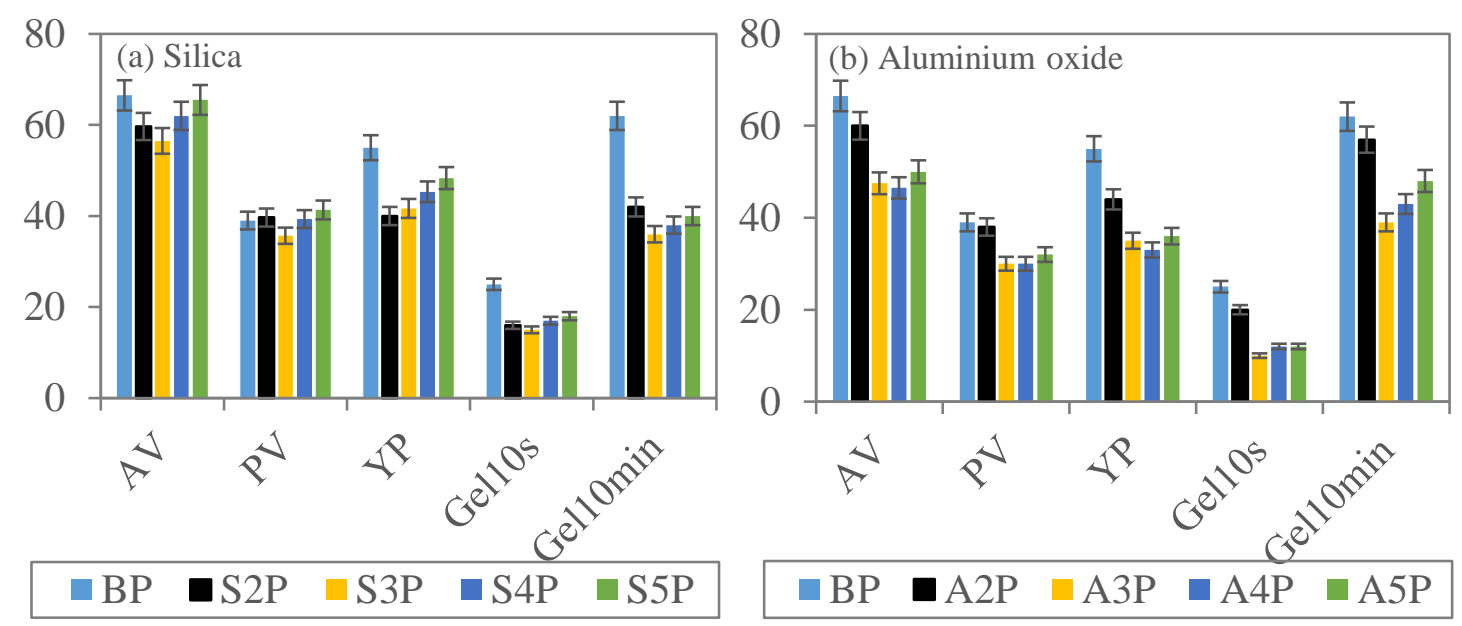

Figure 5: Rheological properties of enhanced WBF with (a) silica NPs (b) aluminium oxide NPs, at $23{ }^{\circ} \mathrm{C}$ and $14.7 \mathrm{psi}$ (AV [cp], PV [cp], YP[lbf/100ft $\left.{ }^{2}\right]$, Gellos [lbf/100ft $\left.{ }^{2}\right]$, GellOmin [lbf/100ft $\left.{ }^{2}\right]$ )

The NPNT filtration test was conducted for seven cases, a base sample, three samples with different concentrations of silica NPs, and the same concentrations with aluminium 
oxide NPs. As shown in Figure 6, the filtrate volume did not increase significantly with NPs concentration of $0.1 \mathrm{wt} \%$, where the filtrate volume remains approximately $6 \mathrm{ml} \pm$ $0.5 \mathrm{ml}$. For NPs concentration of $0.5 \mathrm{wt} \%$ of either aluminium oxide or silica, a large increase in filtrate volume was observed.

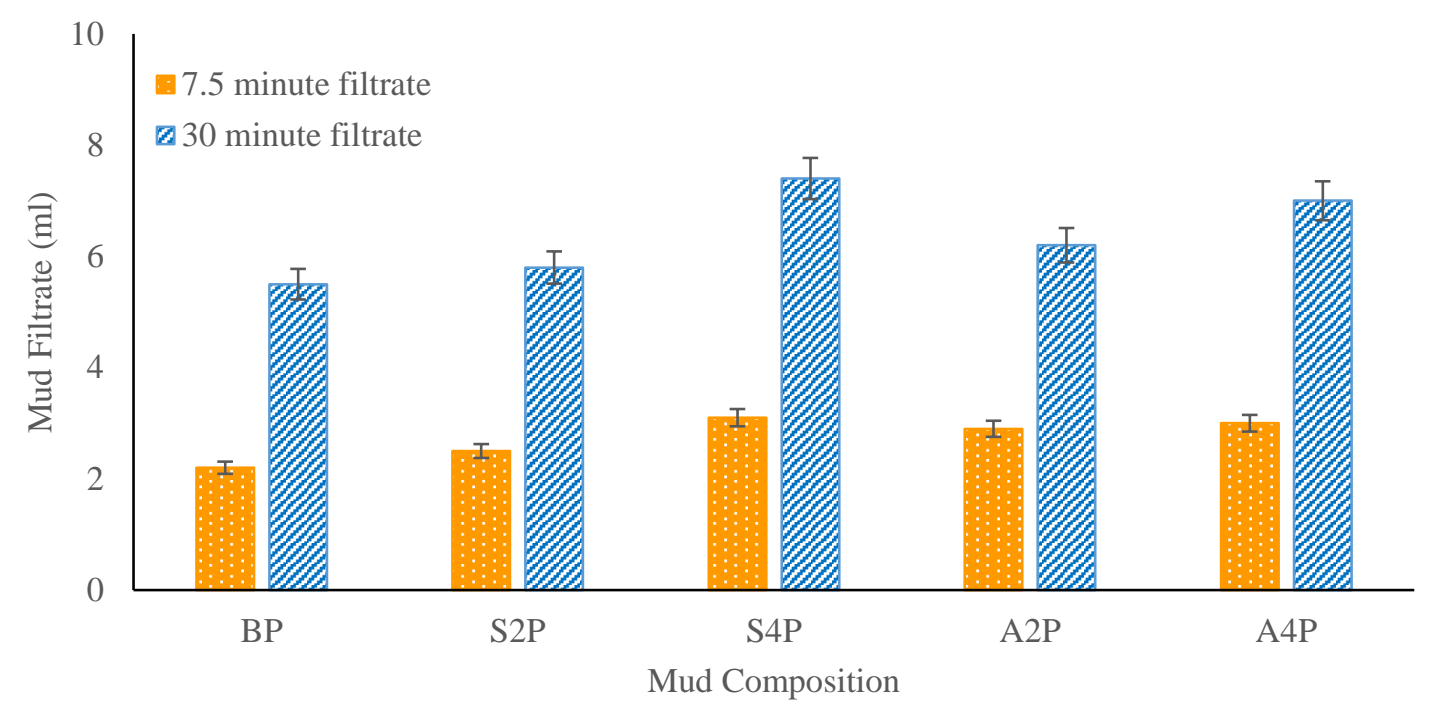

Figure 6: filtrate volume at 7.5-minute and 30-minute

Ideally, Figure 7 shows the theory behind adding NPs into drilling fluids to reduce filtrate volume. Hydrostatic pressure, forces the NPs into the small pores and effectively plugs them. This reduces pore space and permeability of the filter cake which in turn will reduce filtrate volume. However, the filteration results of this study indicate that such plugging process has not been happened. This is possibly due to poor dispersion of NPs inside the WBF, as samples were left for 16 hours for aging, therefore gravitational separation allows the NPs to form agglomerates which then act as much larger particles.
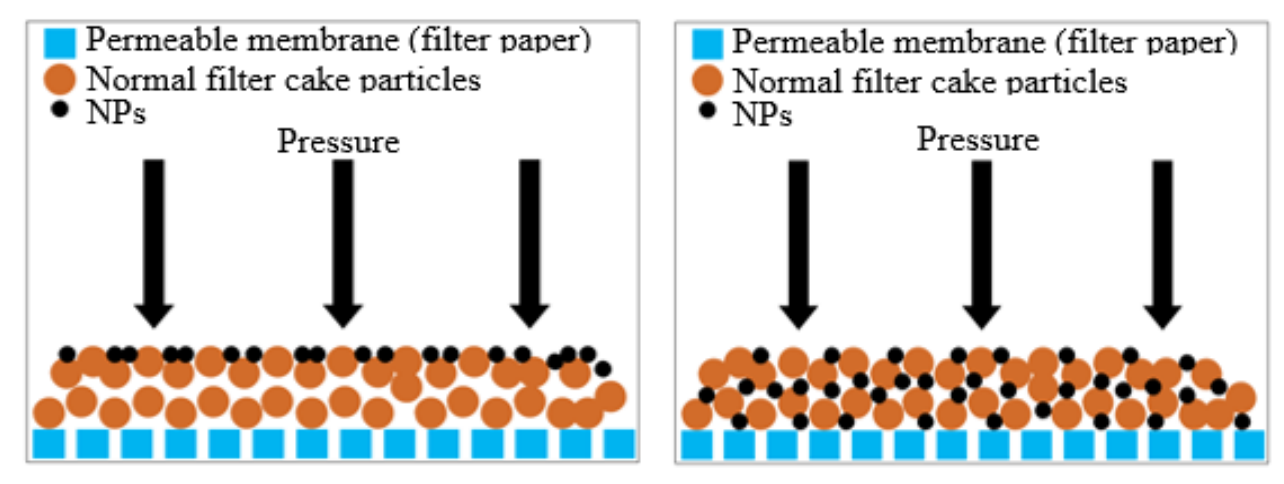

Figure 7: Ideal filter cake NPs starting to push into the filter cake (Left), NPs penetrating filter cakes(Right), closing pores and hence reducing porosity and permeability. 


\section{Rheological and fluid loss properties of a WBF at HPHT condition}

The tests at HPHT conditions were conducted to simulate realistic downhole conditions and to improve our understanding of how the drilling fluid will perform in practice. The rheology tests of the samples were conducted at 50 and $80{ }^{\circ} \mathrm{C}$. Above $80{ }^{\circ} \mathrm{C}$ the basic WBF would breakdown and the rheology tests cannot be performed without additional pressure, otherwise water would evaporate from the fluid samples. HPHT filtration was conducted at $120^{\circ} \mathrm{C}$ and 500 psi based on the standard API procedure. Furthermore, rheology and filtration properties of three samples were assessed before and after hot rolling for 16 hours at $120{ }^{\circ} \mathrm{C}$ and 100 psi. This scenario can give the most realistic evaluation of the drilling fluids performance.

Figure 8 shows shear stress against shear rate at temperatures of 20,50 and $80{ }^{\circ} \mathrm{C}$ for all the samples. BP and A2P samples all were broken down at temperatures of 50 and $80{ }^{\circ} \mathrm{C}$, therefore they were not included. It can be seen from Figure 8 that, all the samples produced clear shear thinning behaviours. The samples with $0.2 \mathrm{wt} \%$ and above showed little degradation from $50-80{ }^{\circ} \mathrm{C}$. The samples with aluminium oxide NPs produced a lower rheology profile compared to the samples with silica NPs which is consistent with the results obtained at NPNT conditions.
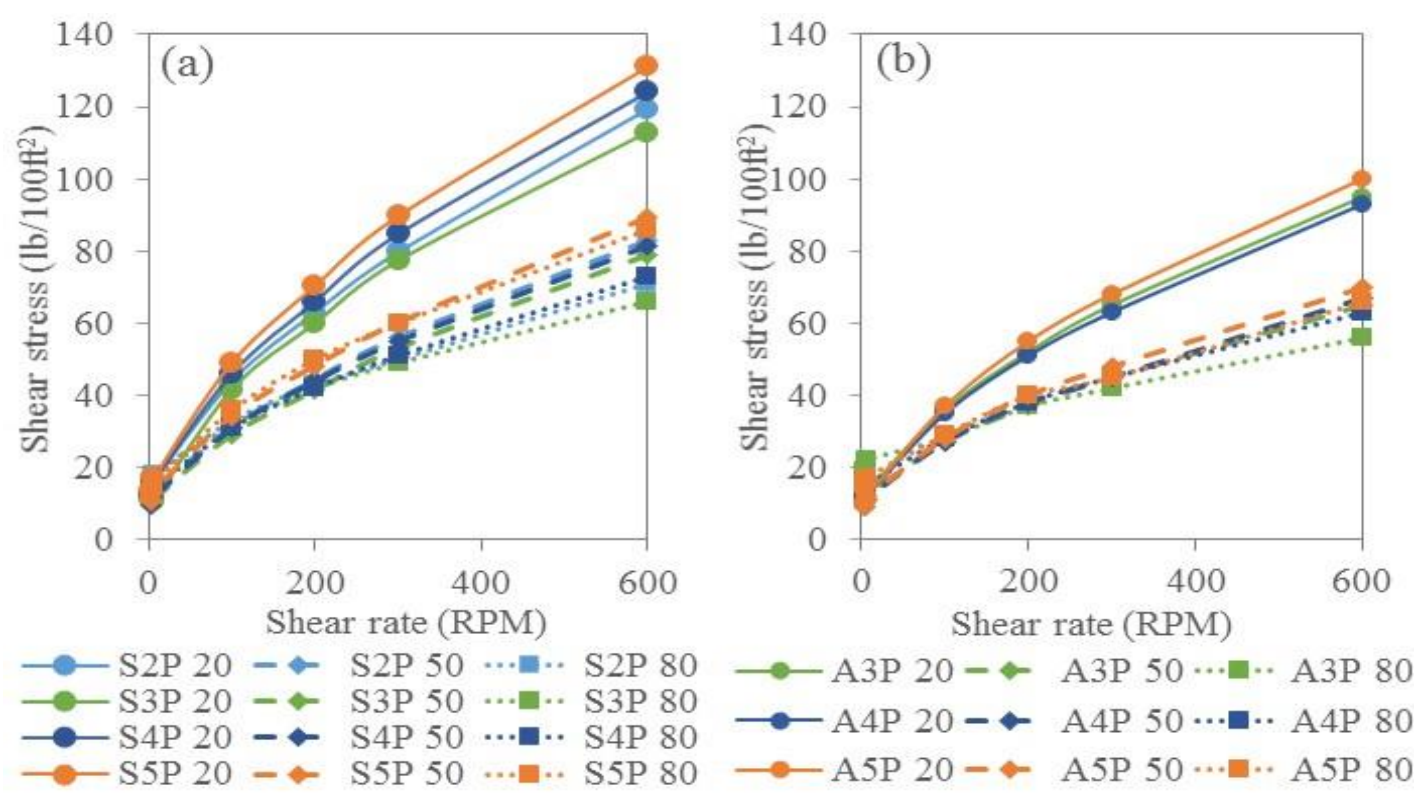

Figure 8: Shear stress against shear rate at elevated temperatures for WBF enhanced with (a) silica NPs (b) aluminium oxide NPs. (BP and A2P samples omitted due to breaking down before $80^{\circ} \mathrm{C}$ ) 
Figure 9 shows the apparent viscosity (AV), plastic viscosity (PV), yield point (YP), and gel strength (Gel10s, Gel10min) properties of nanofluids at the elevated temperatures. Base sample, BP, displayed high values for rheological properties at $50{ }^{\circ} \mathrm{C}$ compared to the samples with nanoparticles. The gel strength is reduced at 50 and $80{ }^{\circ} \mathrm{C}$ by the addition of silica NPs and it levels out at higher concentrations of NPs, whereas, the samples with aluminium oxide NPs with concentrations of $0.2 \mathrm{wt} \%$ and above, showed that their rheological properties decrease and then start to rise again as the concentration increases at $50{ }^{\circ} \mathrm{C}$, and this behaviour was observed around $0.5 \mathrm{wt} \%$ at $80^{\circ} \mathrm{C}$. The gel strength at 10-minutes significantly decreases for the samples containing aluminium oxide NPs at 80 ${ }^{\circ} \mathrm{C}$ compared to silica NPs.
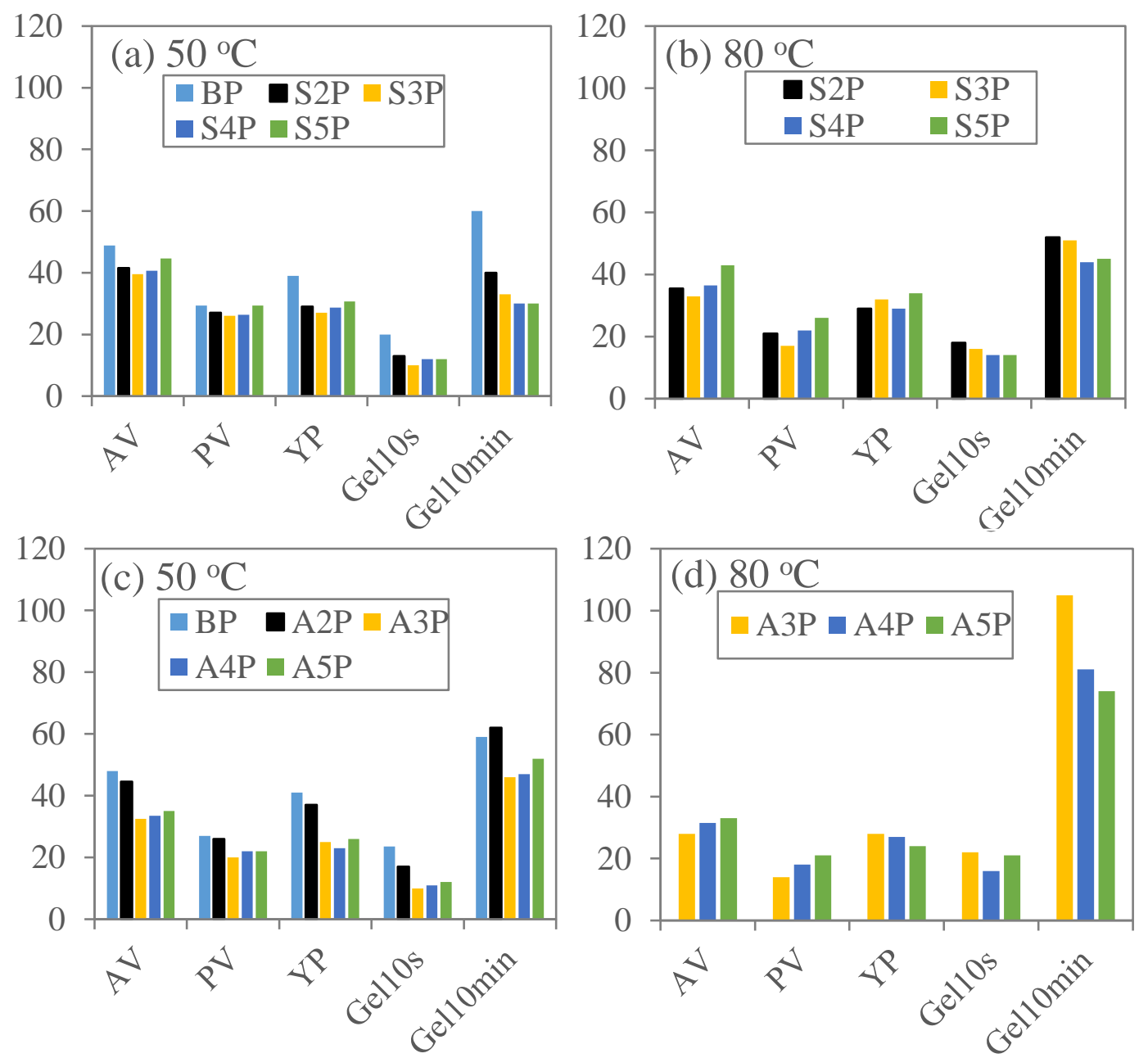

Figure 9: Rheology readings and properties at elevated temperatures of NP enhanced $W B F$ with (a) silica $N P s$ at $50^{\circ} \mathrm{C}\left(\right.$ b) silica $N P s$ at $80^{\circ} \mathrm{C}(\mathrm{c})$ aluminium oxide NPs at 50 ${ }^{\circ} \mathrm{C}(d)$ aluminium oxide NPs at $80{ }^{\circ} \mathrm{C},\left(\mathrm{AV}[\mathrm{cp}], \mathrm{PV}[\mathrm{cp}], \mathrm{YP}\left[\mathrm{lbf} / 100 \mathrm{ft}{ }^{2}\right]\right.$, Gellos [lbf/100ft $t^{2}$, Gel10min[lbf/100ft $\left.t^{2}\right]$ ) 
Figure 10 shows the percentage of decrease in the apparent viscosity (AV), plastic viscosity (PV), yield point (YP), and gel strength (Gel10s, Gel10min). For the change in temperature from ambient temperature up to $50^{\circ} \mathrm{C}$, rheological properties for both types of samples with aluminium oxide and silica NPs, decreased by $15-35 \%$. Gel strength for all samples with silica decreased, however, for the samples with aluminium oxide NPs, it showed a various behaviour but all within $20 \%$ of changes.

For the change in temperature from 50 to $80^{\circ} \mathrm{C}$, samples with silica and aluminium oxide NPs demonstrated no significant differences between the two types of NPs. Both types of NPs show a decrease in viscosity with increase in the concentration. Yield point stays almost constant as all the samples show either an increase or little difference from the values measured at $50{ }^{\circ} \mathrm{C}$. Gel strength of all samples at 10 seconds and 10 minutes, show that they are increased, and the samples containing aluminium oxide NPs have a significantly larger increase.

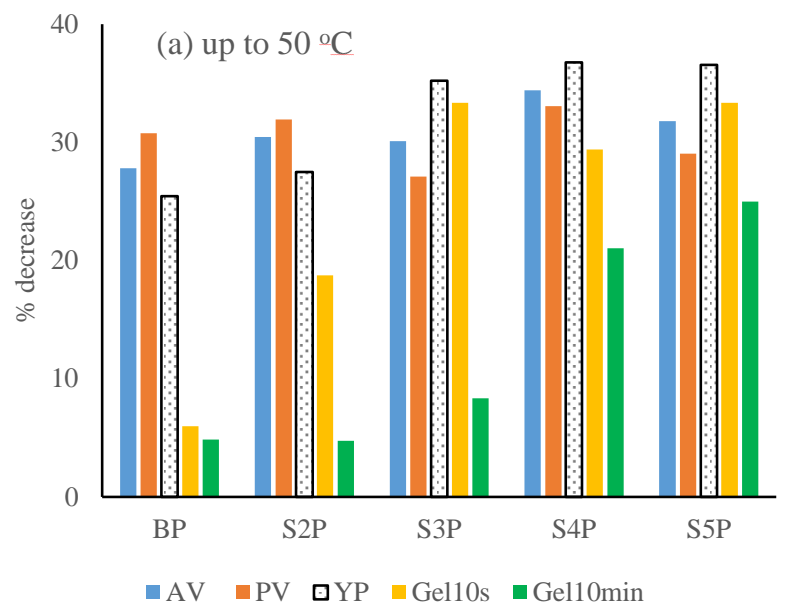

(b) $50 \stackrel{\circ}{\mathrm{C}}$ up to $80 \stackrel{\circ}{\mathrm{C}}$
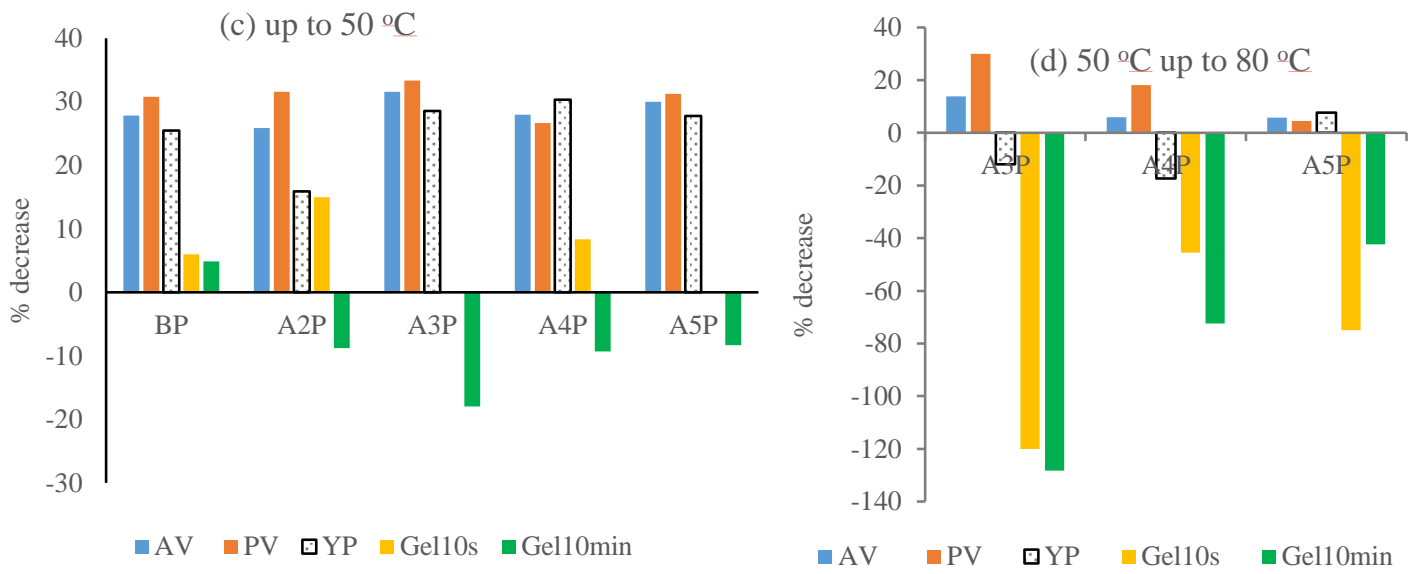
Figure 10: Percentage decrease in rheology properties (a) silica NPs up to $50{ }^{\circ} \mathrm{C}(\mathrm{b})$ silica $\mathrm{NPs}$ from $50^{\circ} \mathrm{C}$ up to $80^{\circ} \mathrm{C}(\mathrm{c})$ aluminium oxide $\mathrm{NPs}$ up to $50^{\circ} \mathrm{C}(\mathrm{d})$ aluminium oxide $\mathrm{NPs}$ from $50^{\circ} \mathrm{C}$ up to $80^{\circ} \mathrm{C}$

The HPHT filtration results are presented in Figure 11 for both samples with silica, and aluminium oxide NPs. The samples with silica NPs showed a general consistent decreasing trend with increase in the NPs concentration up to $1.0 \mathrm{wt} \%$, thereafter the filtrate volume increases significantly as the filtration experiment did not create a solid, dense filter cake suggesting there is high permeability and porosity filter cake allowing fluid to flow through.

The samples with aluminium oxide NPs, show that the filtrate volume increases with increasing concentration of NPs. The largest increase in filtrate volume is for samples with NPs concentrations between 0 to $0.1 \mathrm{wt} \%$, then subsequently the rate of increase in filtrate volume reduces, thus indicating the filter cake may approach to the saturation limit of holding the aluminium oxide NPs.
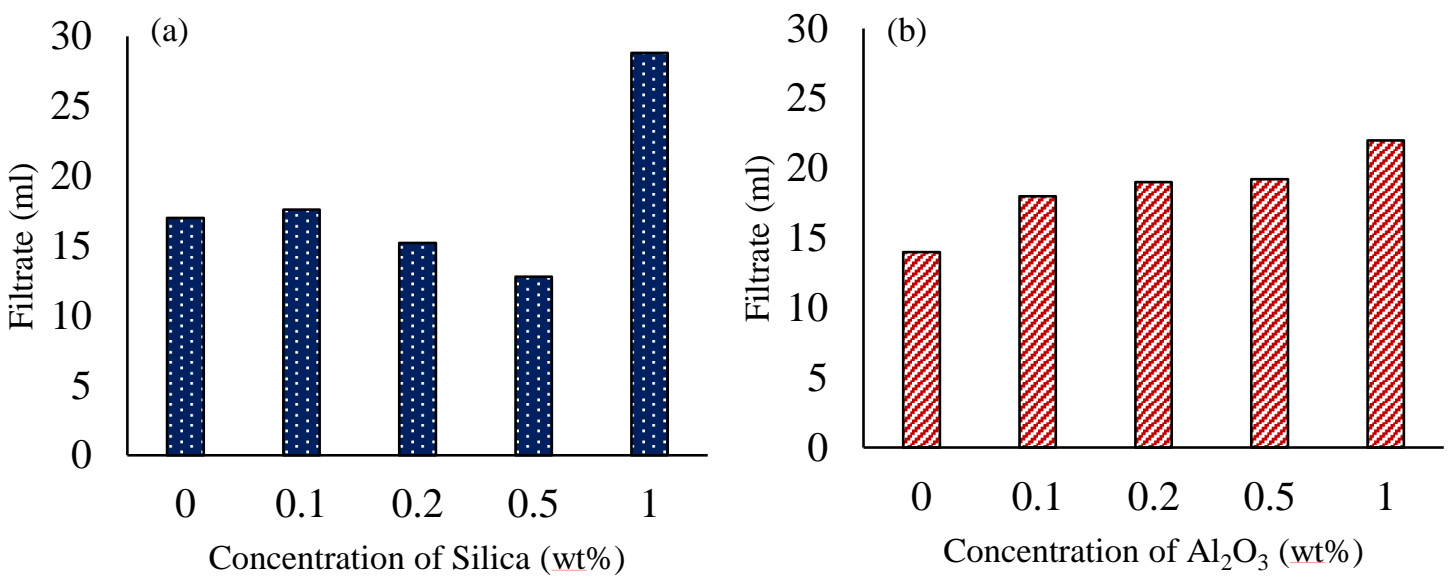

Figure 11: HPHT 30-minute filtrate at $120^{\circ} \mathrm{C} / 500$ psi for different concentration of $\mathrm{NPs}\left(\right.$ a) silica (b) aluminium oxide $\left(\mathrm{Al}_{2} \mathrm{O}_{3}\right)$

Figure 12 shows that the colour of the filtrate of silica NPs is white (milky) which is similar in colour to the aluminium oxide NPs dispersion in deionised water suggesting both types of NPs have flowed through the filter paper, while it was noted that the filtrate of the base sample was clear. Other mud ingredients have particle sizes ranging between 1 to $100 \mu \mathrm{m}$, and the particle size retention range for the filter paper is $2-5 \mu \mathrm{m}$, hence particles of bentonite, barite and PAC may not penetrate through the filter paper, and the filtrate is getting its colour from the NPs. Having a small particle sizes range between 1- 
$100 \mu \mathrm{m}$ and a simple fluid formulation with few additives is likely causing a poor compaction of the filter cake allowing for the NPs to easily flow through the filter cake and then through the filter paper as the size of NPs are $12 \mathrm{~nm}$ for silica, and $<50 \mathrm{~nm}$ for aluminium oxide.

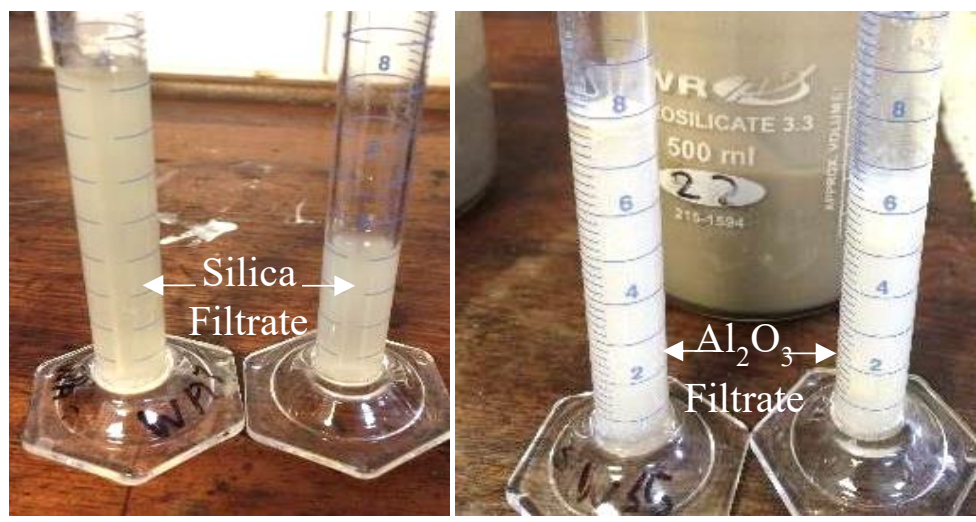

Figure 12: Image of filtrate of S5P sample (Left), A5P sample (Right) after filtration test. S5P sample is shown in the glass container to show difference in colour between sample and its filtrate

A typical particle size distribution of a drilling fluid is shown in Figure 13 [32]. It displays that particle size distribution in drilling fluids typically ranges from $0.001 \mathrm{~mm}$ up to 1 mm which was confirmed by several other studies [33-35], whereas the particle size distribution of the drilling fluid used in this study was between $0.001 \mathrm{~mm}$ and $0.1 \mathrm{~mm}$ before the addition of NPs. If the fluid formulation is more complex with a wider range of particle size distribution including a rise in particle size less than $0.001 \mathrm{~mm}$, and larger NPs with particle size distribution around $10-100 \mathrm{~nm}$, this would likely result in a desired effect as other studies have reported that NPs contribute to creation of a thinner, more compact filter cake that will reduce filtration.

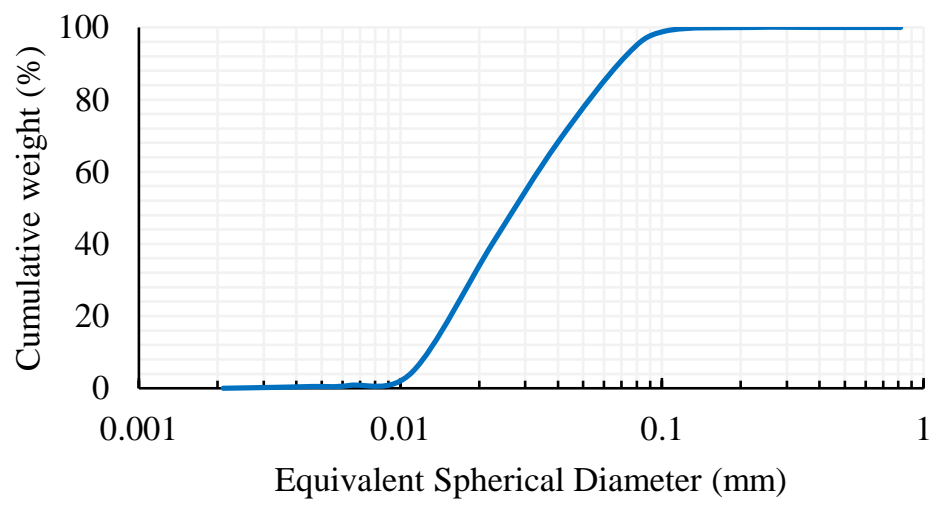

Figure 13: Typical particle size distribution in a drilling fluid adapted from [32] 
Dynamic ageing, typically done at temperatures greater than $120{ }^{\circ} \mathrm{C}$, is important to conduct as a drilling fluid is being subject to a high temperature over time, where the components of the drilling fluid can be degraded, and it may cause a negative effect on the drilling fluids performance.

Figure 14 shows the rheology profile and rheological properties of three samples before and after dynamic ageing. The rheology profile shows that three samples exhibited very similar shear stress against shear rate before dynamic ageing. However, after dynamic aging, the base sample and the sample with $0.2 \mathrm{wt} \%$ of silica showed a significant increase in the rheology, whereas the sample with aluminium oxide NPs showed an increase in the rheology, but it was not as significant as observed for the other samples.
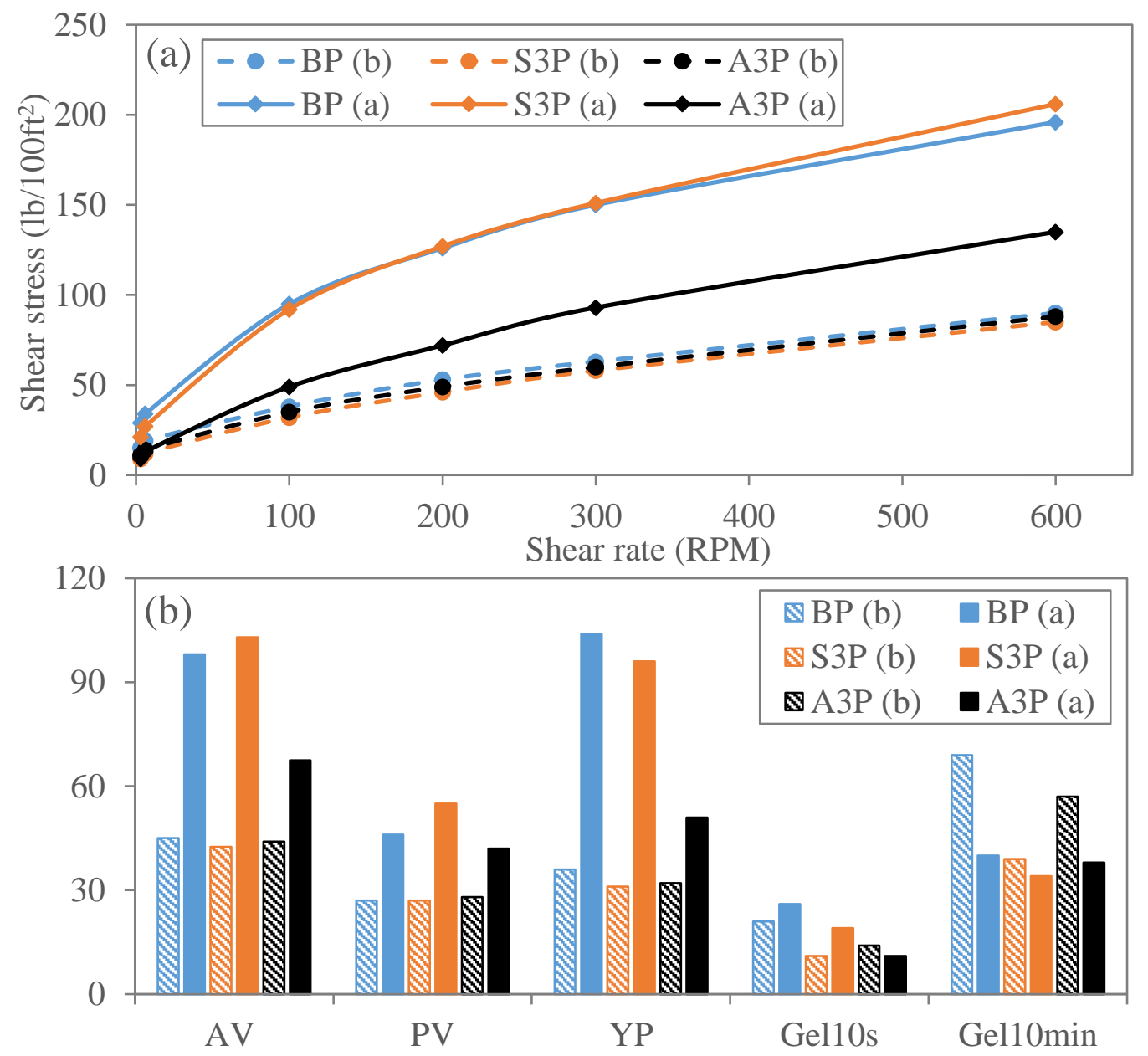

Figure 14: (a) Shear stress against shear rate (b) Rheology properties before and after hot rolling at $120^{\circ} \mathrm{C}$ and 100 psi for 16 hours, (AV [cp], PV [cp], YP[lbf/100ft $\left.{ }^{2}\right]$, Gellos [lbf/100ft ${ }^{2}$ ], Gel10min[lbf/100ft $\left.{ }^{2}\right]$ )

The rheological properties before hot rolling show similar viscosities for all three samples, and similar yield points for two samples containing NPs. However, the gel 
strengths have shown different ranges. Apparent viscosity and yield point increased significantly by over $100 \%$ and around $200 \%$ respectively, after hot rolling for the BP and S3P samples, but they only increase by around $50 \%$ for the A3P sample (see supplementary material for more details on the changes in rheological properties). Plastic viscosity was also increased for all the samples, with the A3P sample having the lowest increase, and the S3P sample showing the highest value. 10-second gel strength for the base and A3P samples, showed a little difference before and after hot rolling, whereas, the S3P sample showed a large increase after hot rolling. On the other side, for 10-minute gel strength, all the samples showed a decrease in the gel strength after hot rolling, while the S3P sample demonstrated the lowest decrease, and remained close to the value that was observed before hot rolling.

We tried to compare our experimental data with other studies. As shown in Figure 15, the obtained results for shear stress against shear rate for $0.5 \mathrm{wt} \%$ silica NPs at different temperatures were compared with Mahmoud et al.'s work [26]. It can be seen from this figure, both studies suggested shear thinning trends with different orders of magnitude due to different mud compositions. The results show that the magnitude of shear stress was decreased with increasing temperature which could be due to thinning effect of temperature on viscosity of drilling fluids at higher temperatures. However, Mahmoud et al.'s data, showed a slight increase in shear stress at higher temperatures, this might be due to evaporation of liquid phase from the drilling fluid samples they used in their experiments. This demonstrates that an appropriate drilling fluid composition and design is critical to improve the performance of drilling operation.

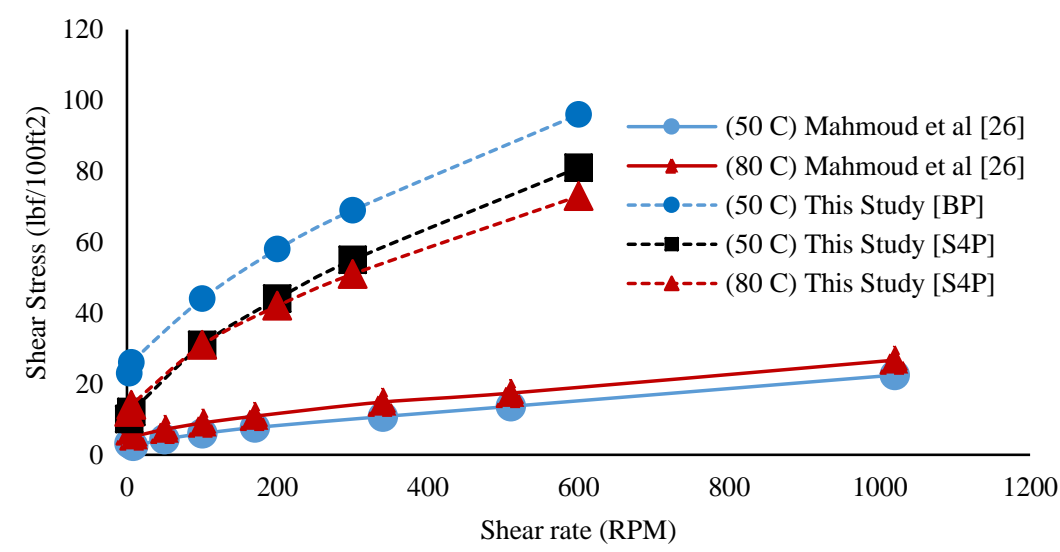

Figure 15: Comparison of Shear Stress against Shear rate for $0.5 \mathrm{wt} \%$ silica at different temperatures 
Also we found that yield point was increased with increasing temperature for drilling fluids with silica NPs as shown in Figure 16. This is a consistent trend in both the current investigation and the study performed by Mahmoud et al. [26], however, the difference in the magnitude of yield pints is due to the composition of drilling fluids used in these studies.

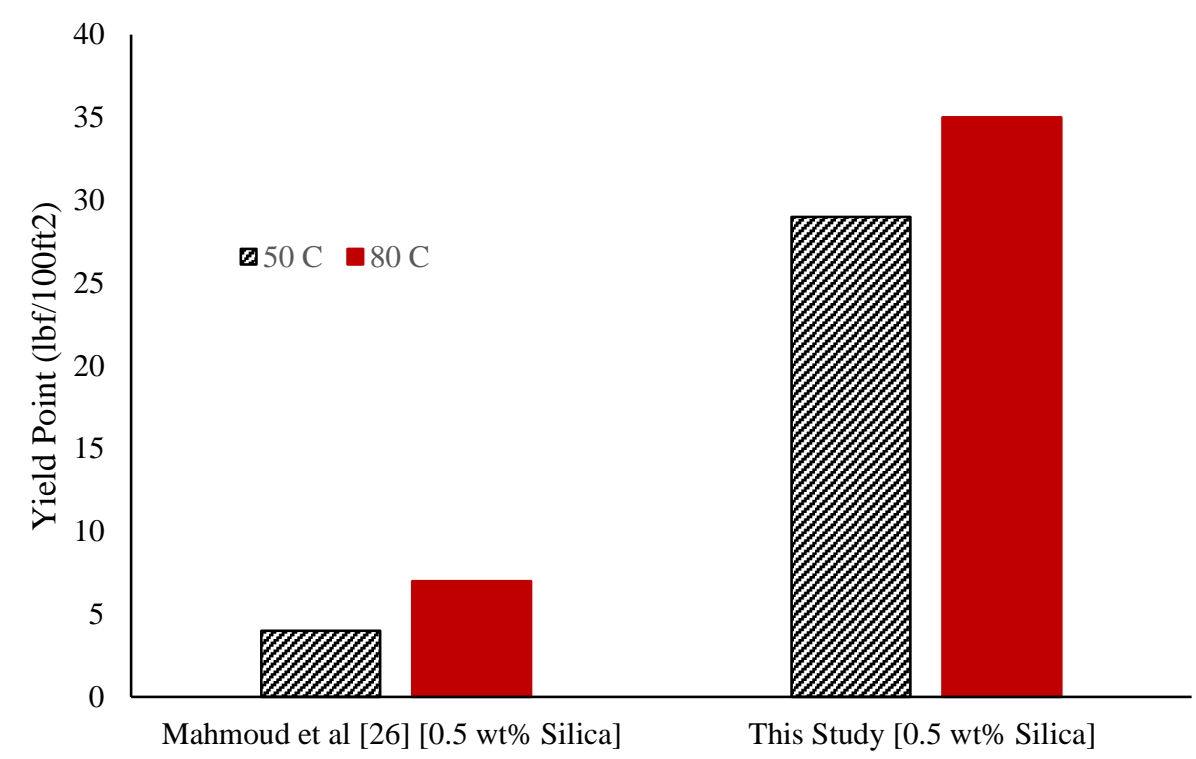

Figure 16: Comparison of yield point for drilling fluids with 0.5 wt\% silica NPs at different temperatures

Furthermore, Mahmoud et al., 2016, conducted experiments on a bentonite WBF with ferric oxide NPs instead of aluminium oxide NPs used in our study, but the same nanoparticle diameters of less than $50 \mathrm{~nm}$. They measured the plastic viscosity and yield point values of the samples with $0.5 \mathrm{wt} \%$ of ferric oxide NPs before and after thermal ageing at $177^{\circ} \mathrm{C}$ for 16 hours. The plastic viscosity for the sample with ferric oxide NPs displayed consistent values across a range of temperatures showing more stability compared to their samples with silica NPs. This is comparable to the results obtained in our investigation where aluminium oxide samples had much less degradation after ageing compared to silica samples, hence showing improved stability through the use of metal nanoparticles. Same trends were reported for yield point values as yield point was increased significantly with the silica NPs (same observation with the S3P sample in this study after ageing). However, the yield point for ferric oxide NPs remained relatively similar after and before aging (again similar observation obtained with the A3P sample in our study). This suggests the use of metal NPs could improve drilling fluids 
performance through their enhanced heat conductivity, which can help heat dissipation and reduce thermal degradation effects on downhole equipment.

Figure 17 shows the HPHT filtrate volume before and after dynamic ageing, and the percentage rise between them. The A3P sample showed the best performance with around $20 \%$ increase compared to the S3P sample which produced a poor performance with filtration increasing by over $75 \%$, higher than the base sample at just less than $60 \%$.
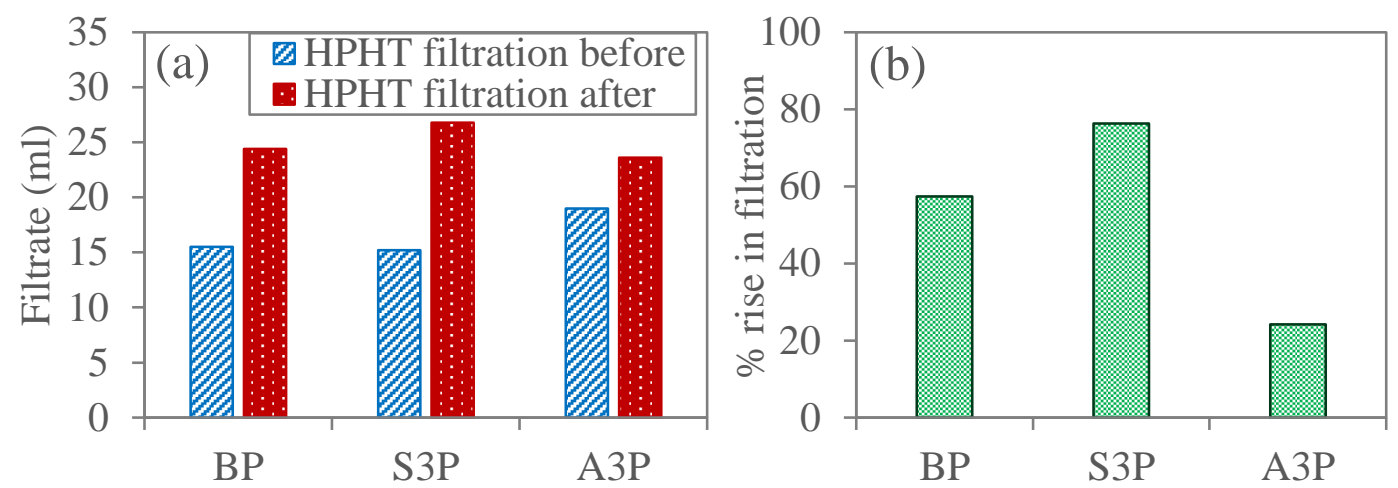

Figure 17: (a) HPHT filtration before and after hot rolling (b) percentage rise in filtration after hot rolling

The mud filtration results of this study were compared with data reported by Mahmoud et al. [26]. Their results were recorded at $300 \mathrm{psi}, 120^{\circ} \mathrm{C}$, that are fairly similar to our work at $500 \mathrm{psi}, 120^{\circ} \mathrm{C}$ as shown in Figure 18. Both studies showed that the mud filtration at concentrations around $1 \mathrm{wt} \%$ was increased, which is probably due to silica NPs agglomeration observed in our experiment making the filtration properties worse.

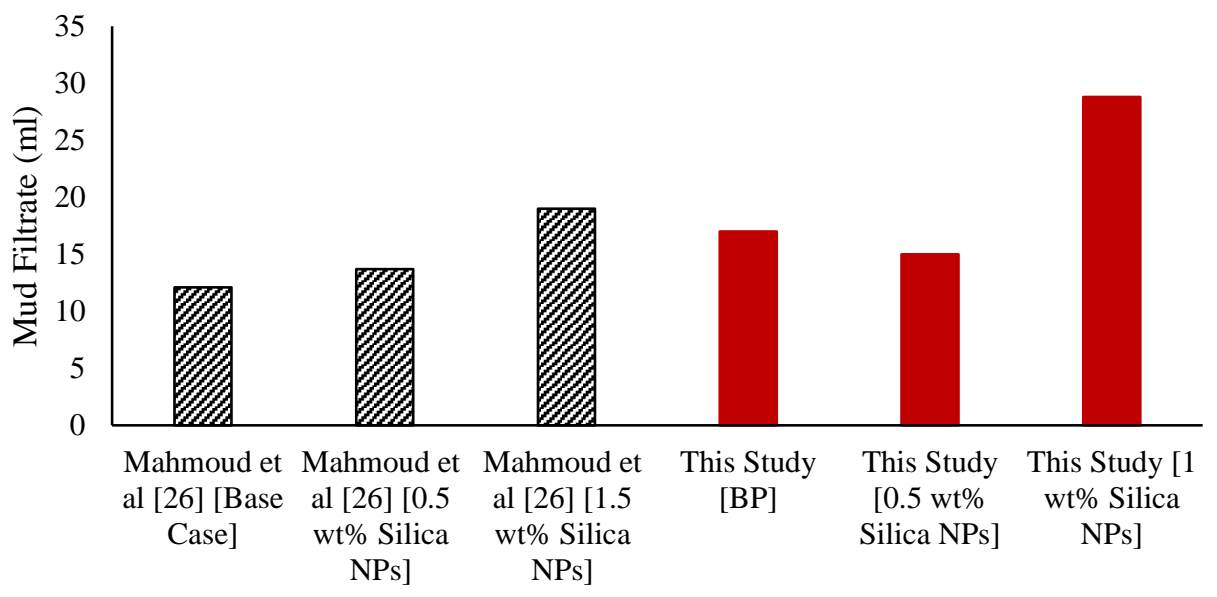

Figure 18: Comparison of mud filtrate for different silica NPs concentrations 
Figure shows images of the filter cakes produced after HPHT filtration for the samples have been dynamically aged. The images showed no noticeable difference in the filter cakes of three samples. However, SEM analysis is recommended for further microscopic studies.
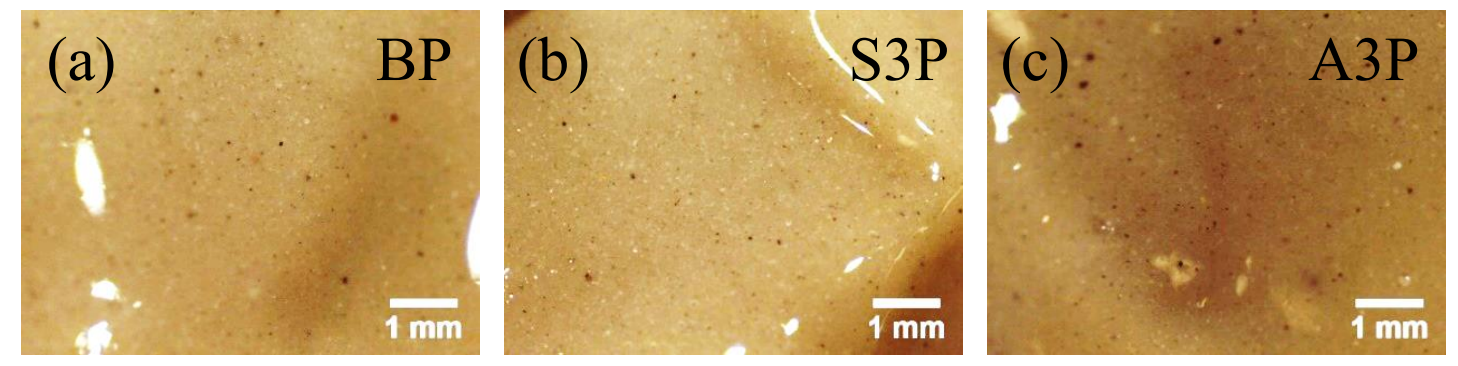

Figure 19: Surface images of filter cakes produced after the HPHT filtration (a) BP (b) S3P (c) A3P.

In summary, the samples with NPs produced dissatisfactory results at NPNT conditions as they showed little or negative effects on the fluid properties, with filtration increasing and significantly lower rheology. This is likely due to fact that the samples were being left statically for aging purposes at ambient temperature with no pressure, therefore the NPs were allowed to agglomerate. The filter paper has particle size retention range of 0.002-0.005 mm, therefore the NPs likely penetrated through the paper. Furthermore, images showed that the filtrate had similar milky colour for both types of WBF with NPs. However, further microscopic investigation of mud filtrate is required in order to determine if this is the case.

The HPHT tests showed that increasing the concentration of NPs decreased the degradation effect, with only the base samples and the samples with low concentrations breaking down completely at $80{ }^{\circ} \mathrm{C}$. The HPHT filtration test, like the NPNT one, showed an increase in filtrate volume with increasing the concentration of aluminium oxide NPs, but there was a decrease in filtrate volume with addition of silica NPs except at $1.0 \mathrm{wt} \%$ where it produced a significant increase. Again, this is likely due to agglomeration of the silica NPs, so that they act like larger particles and may not perform in a way that is expected from NPs to plug the small pores in the filter cake, and they just simply flow through the filter cake and filter paper.

The process of dynamic ageing produced the most realistic results for field applications. The sample with $0.2 \mathrm{wt} \%$ aluminium oxide NPs, after being dynamically aged showed the lowest increase in the rheology profile, and rheological properties (AV, PV, YP, 
Gel10s, and Gel10min) were compared with the base sample and the sample with silica NPs. The results were consistent with previous research, where the sample with silica NPs performed poorly after being aged and the sample with aluminium oxide NPs produced nanofluids that showed lower degradations. The HPHT filtration after hot rolling showed that the sample with aluminium oxide NPs produced the lowest increase in the filtrate volume at just over $20 \%$, whereas the other two samples showed increases in the filtrate volume by over $60 \%$. The superior thermal performance of the drilling fluid with aluminium oxide NPs at $0.2 \mathrm{wt} \%$ is due to being at a low concentration which may not agglomerate, and being dynamically aged which prevented agglomeration. The aluminium oxide NPs themselves have significantly higher thermal conductivity than the silica NPs and hence displayed superior heat dissipation through the fluid with Brownian motion.

A summary of the rheology and filtration properties at NPNT, HPHT and post-dynamic ageing for the addition of silica and aluminium oxide NPs is shown in Table 3. This shows the biggest difference between the NPs is in their effects on the WBF after being dynamically aged, where aluminium oxide NPs out-performed the silica NPs.

Table 3 Summary of the effects of adding silica and aluminium oxide NPs on rheology and filtration properties.

\begin{tabular}{|l|l|l|}
\hline & Silica NPs & Aluminium oxide NPs \\
\hline NPNT rheology & Decreases steadily & $\begin{array}{l}\text { Decreases sharply at 0.2 wt\% and } \\
\text { above }\end{array}$ \\
\hline NPNT filtration & $\begin{array}{l}\text { Increases steadily with greater } \\
\text { concentration }\end{array}$ & $\begin{array}{l}\text { Increases steadily with greater } \\
\text { concentration }\end{array}$ \\
\hline HPHT rheology & $\begin{array}{l}\text { Less degradation at higher } \\
\text { concentration }\end{array}$ & $\begin{array}{l}\text { Less degradation at higher } \\
\text { concentration }\end{array}$ \\
\hline HPHT filtration & $\begin{array}{l}\text { General decrease and then } \\
\text { increases sharply at 1 wt\% }\end{array}$ & $\begin{array}{l}\text { Increases steadily with rising } \\
\text { concentration }\end{array}$ \\
\hline Post-dynamic ageing & $\begin{array}{l}\text { Large rise in properties } \\
\text { comparative to base sample }\end{array}$ & $\begin{array}{l}\text { Relatively lower rise in properties. } \\
\text { Out-performs silica and base } \\
\text { sample }\end{array}$ \\
\hline $\begin{array}{l}\text { Post-dynamic ageing } \\
\text { HPHT filtration }\end{array}$ & $\begin{array}{l}74 \% \text { increase (base sample } \\
\text { increased 57\%) }\end{array}$ & $\begin{array}{l}\text { 24\% increase (base sample } \\
\text { increased 57\%) }\end{array}$ \\
\hline
\end{tabular}




\section{Conclusions and recommendations}

This research aimed at developing an environmentally friendly alternative for oil based drilling fluids, a water based drilling fluid with enhanced properties through addition of aluminium oxide nanoparticles. This new WBF needs to have similar performance to oil based drilling fluids at HPHT conditions. The addition of aluminium oxide nanoparticles up to $1 \mathrm{wt} \%$ was tested, and the results were compared with the samples with silica nanoparticles and the base sample with no nanoparticles. The results showed that the dispersion of aluminium oxide nanoparticles increased the thermal stability of the fluid, considerably more than the base sample and the sample with silica NPs.

Overall aluminium oxide NPs in low concentrations enhanced the thermal stability of the WBF and provided lower degradations compared to the base sample and the samples with silica NPs. This was shown from the results of the post-dynamic ageing experiments, where the HPHT filtration for the sample with aluminium oxide NPs had lower increase in filtrate volume than the base sample, and the sample with silica NPs, and rheology tests demonstrated a lower increase in shear stress for the sample with aluminium oxide NPs compared to the base sample and the sample with silica NPs.

This research has touched a minor part of the extensive testing required for any new additives hence the following recommendations for further research are proposed:

1. Testing different fluid formulations including OBF with added NPs to be able to evaluate the properties of other nanofluids for drilling operations. Using a more complex formulation with more additives which provide a wider particle size distribution with the possibility of reducing filtrate volume rather than increasing it.

2. Investigate a greater range of temperature and pressure conditions. Temperatures from $0{ }^{\circ} \mathrm{C}$ up to as high as $160{ }^{\circ} \mathrm{C}$ and rheology at heightened pressure as it was at atmospheric throughout the rheology experiments.

\section{Acknowledgments}

Authors would like to thank the School of Engineering at the University of Aberdeen for providing required consumables and facilities to complete this research.

We would also like to thank Halliburton for their permission to conduct part of experiments in the drilling fluid laboratories in Dyce, Aberdeen, and their feedback and comments throughout research. 


\section{References}

[1] U.S. Energy Information Administration, Trends in U . S . Oil and Natural Gas Upstream Costs. March, 2016.

[2] J.R. Smith, Energy demand creates new opportunities and challenges for drilling, J. Can. Pet. Technol., 40 (05) (2001).

[3] J.M. Shaughnessy, L.A. Romo, B.P. America, R.L. Soza, B. Resources, Problems of Ultra-Deep High-Temperature , High-Pressure Drilling, paper presented at SPE annual technical conference and exhibition, 5-8 Oct 2003, Denver, Colorado, USA.

[4] R.G. Bland, G.A. Mullen, Y.N. Gonzalez, F.E. Harvey, M.L. Pless, HPHT Drilling Fluid Challenges, paper presented at IADC/SPE Asia Pcific Drilling Conference, 13-15 Nov 2006, Bangkok, Thiland.

[5] K. Bybee, Water-Based Drilling-Fluid Systems for Deepwater Norway, JPT, 53 (11)(2001), 36-36.

[6] J. Elward-Berry, E.W. Thomas, Rheologically Stable Deepwater Drilling Fluid Development and Application, paper presented at IADC/SPE Drilling Conference, Dallas, Texas, 15-18 February 1994.

[7] M. Amani, M. Al-Jubouri, A. Shadravan, Comparative study of using oil-based mud versus water-based mud in HPHT fields. Advances in Petroleum Exploration and Development, 4(2) (2012)18-27.

[8] J.T. Srivatsa, M.B. Ziaja, An experimental investigation on use of nanoparticles as fluid loss additives in a surfactant-polymer based drilling fluids, paper presented at International Petroleum Technology Conference, 15-17 Nov 2011 Bangkok, Thailand.

[9] J. Abdo, M.D. Haneef, Clay nanoparticles modified drilling fluids for drilling of deep hydrocarbon wells, Appl. Clay Sci., 86 (2013)76-82.

[10] Y. Dahman, Chapter 5-Nanoparticles, in: Nanotechnology and Functional Materials for Engineers, Ed: Elsevier, 2017, pp. 93-119.

[11] I.N. Evdokimov, N.Y. Eliseev, A.P. Losev, M.A. Novikov, Emerging PetroleumOriented Nanotechnologies for Reservoir Engineering, paper presented at SPE Russian Oil Gas Technology Conference \& Exhibition. 3-6 October 2006, Moscow, Russia.

[12] M.F. Fakoya, S.N. Shah, Emergence of nanotechnology in the oil and gas industry: Emphasis on the application of silica nanoparticles, Petroleum (2017).

[13] R. Rafati, A. Sharifi Haddad, H. Hamidi, Experimental study on stability and rheological properties of aqueous foam in the presence of reservoir natural solid particles. Colloids and Surf. A 509 (2016) 19-31.

[14] Y. Kang, J. She, H. Zhang, L. You, M. Song, Strengthening shale wellbore with silica nanoparticles drilling fluid, Petroleum, 2 (2016) 189-195. 
[15] H. Mao, Z. Qiu, Z. Shen, W. Huang, Hydrophobic associated polymer based silica nanoparticles composite with core-shell structure as a filtrate reducer for drilling fluid at utra-high temperature, J. Pet. Sci. Eng. 129 (2015) 1-14.

[16] H. Mao, Z. Qiu, Z. Shen, W. Huang, H. Zhong, W. Dai, Novel hydrophobic associated polymer based nano-silica composite with core-shell structure for intelligent drilling fluid under ultra-high temperature and ultra-high pressure, Prog. Nat. Sci., 25(2015) 90-93.

[17] S.M. Javeri, Z.M.W. Haindade, C.B. Jere, Mitigating Loss Circulation And Differential Sticking Problems Using Silicon Nanoparticles, paper presnted at: SPE/IADC Middle East Drilling Technology Conference and Exhibition 24-26 October 2011, Muscat, Oman.

[18] S. Sadegh Hassani, A. Amrollahi, A. Rashidi, M. Soleymani, S. Rayatdoost, The effect of nanoparticles on the heat transfer properties of drilling fluids, J. Pet. Sci. Eng. 146 (2016)183-190.

[19] A. Einstein, Investigations on the Theory of the Brownian Movement. Courier Corporation, 1956.

[20] M.S., Liu, M.C.C. Lin, I.T. Huang, C.C. Wang, Enhancement of thermal conductivity with carbon nanotube for nanofluids, Int. Comm. Heat Mass Trans., 32(9) (2005)1202-1210.

[21] Y. Ding, H. Alias, D. Wen, R.A. Williams, Heat transfer of aqueous suspensions of carbon nanotubes (CNT nanofluids). Int. J. Heat Mass Trans., 49(1) (2006) 240-250.

[22] M. Farbod, A. Ahangarpour, S.G. Etemad, Stability and thermal conductivity of water-based carbon nanotube nanofluids. Particuology, 22 (2015) 59-65.

[23] H.S. Aybar, M. Sharifpur, M.R. Azizian, M. Mehrabi, J.P. Meyer, A review of thermal conductivity models for nanofluids. Heat Transfer Engineering, 36(13) (2015) 1085-1110.

[24] K. Seear, A. Petersen, D. Bowman, The Social and Economic Impacts of Nanotechnologies: A Literature Review, Monash University Victoria, Australia, 2009.

[25] J.G. Xu, Z. Qiu, X. Zhao, W. Huang, Hydrophobic modified polymer based silica nanocomposite for improving shale stability in water-based drilling fluids, J. Pet. Sci. Eng. 153 (2017) 325-330.

[26] O. Mahmoud, H.A. Nasr-El-Din, Z. Vryzas, V. C. Kelessidis, NanoparticleBased Drilling Fluids for Minimizing Formation Damage in HP/HT Applications, paper presented at: SPE International Conference Exhibition on Formation Damage Control, 24-26 Feb 2016, Lafayette, Louisiana, USA.

[27] S. Sang, W. Li, J. Pu, L. Jian, Novel $\mathrm{Al}_{2} \mathrm{O}_{3}$-based compressive seals for ITSOFC applications, J. Power Sources, 177(2008) 77-82.

[28] C. Anyanwu, M.M. Unubi, P. Harcourt, Experimental Evaluation of Particle Sizing in Drilling Fluid to Minimize Filtrate Losses and Formation Damage, paper presented at: SPE Nigeria Annual International Conference and Exhibition, 2-4 August 20016, Lagos, Nigeria. 
[29] E.M. Amarfio, M. Abdulkadir, Effect of $\mathrm{Al}_{2} \mathrm{O}_{3}$ Nanoparticles on Radiolytic $\mathrm{H}_{2} \mathrm{O}_{2}$ Production in Water, J. Physical Chemistry C, 130 (1)(2011) 8144-8149.

[30] J.K.M. William, S. Ponmani, R. Samuel, R. Nagarajan, J.S. Sangwai, Effect of $\mathrm{CuO}$ and $\mathrm{ZnO}$ nanofluids in xanthan gum on thermal, electrical and high pressure rheology of water-based drilling fluids, J. Pet. Sci. Eng. 117 (2014) 15-27.

[31] S. Krishnan, Z. Abyat,C. Chok, Characterization of boron-based nanomaterial enhanced additive in water-based drilling fluids: a study on lubricity, drag, ROP and fluid loss improvement, paper presnted at: SPE/IADC Middle East Drilling Technology Conference and Exhibition, 26-28 January 2016, Abu Dhabi, UAE

[32] H.C. Darley, G.R. Gray, G.R. Composition and properties of drilling and completion fluids, Gulf Professional Publishing, 1988.

[33] M.A. Dick, T.J. Heinz, C.F. Svoboda, M. Aston, Optimizing the selection of bridging particles for reservoir drilling fluids, paper presented at SPE International Symposium on Formation Damage Control. SPE International Symposium on Formation Damage Control, 23-24 February 2000, Lafayette, Louisiana.

[34] A. Suri, M.M. Sharma, Strategies for sizing particles in drilling and completion fluids, SPE J. 9(01) (2004) 13-23.

[35] O. Razavi, A.K. Vajargah, E. van Oort, M. Aldin, S. Govindarajan, Optimum particle size distribution design for lost circulation control and wellbore strengthening, J. Nat. Gas Sci. Eng. 35(2016) 836-850. 